\title{
Uma contribuição à avaliação dos periódicos científicos por meio do Balanced Scorecard: ilustração da avaliação e opera- cionalização da gestão estratégica na RCC
}

A contribution to the evaluation of scientific periodicals through the Balanced Scorecard: illustration of evaluation and implementation of strategic management in RCC

\section{Juliane Vieira de Souza}

Doutranda em Engenharia de Produção na Universidade Federal de Santa Catarina.

Profa. Centro Universitário Leonardo da Vince

Endreço: Rua São Pio X, 133, Residencial Camila, Bairro Coqueiros

CEP: 88080030 - Florianópolis/SC - Brasil

E-mail: juliane.vieiradesouza@gmail.com

Telefone: (48)3247-6071

\section{Sergio Murilo Petri}

Doutor em Engenharia de Produção na Universidade Federal de Santa Catarina

Professor do Mestrado em Ciências Contábeis da Universidade Federal de Santa Catarina

Endereço: Campus Universitário, Bairro Trindade

CEP: 88040- 970 - Florianópolis/SC- Brasil

E-mail: smpetri@gmail.com

Telefone: (48)3721-9383

\section{Mariane de Souza Cardoso}

Mestre em Engenharia de Produção na Universidade Federal de Santa Catarina.

Endereço: Rua Angelo Tulio Baruffi, 144, Bairro Ilha da Figueira

CEP: 89258-550 - Jaraguá/SC - Brasil

E-mail: marianesouzacardoso@ymail.com 


\title{
Resumo
}

O presente estudo tem por objetivo propor a transformação da ação estratégica da Revista Contemporânea de Contabilidade (RCC) em objetivos operacionais, com base na abordagem do Balanced Scorecard (BSC). Trata-se de um estudo de caso de natureza descritiva. Para a coleta de dados, utilizaram-se fontes secundárias disponibilizadas pela revista estudada. Para construção do referencial teórico, realizou-se uma pesquisa bibliográfica nos periódicos internacionais disponibilizados no portal da Capes. A partir deste estudo, foi possível identificar os principais critérios usados para a avaliação dessas publicações. Os resultados apontaram para a proficuidade da proposta que conseguiu identificar 13 objetivos distribuídos em três perspectivas: Sociedade, Processos Internos, e Aprendizagem e Crescimento. A construção do painel estratégico proporcionou a geração dos indicadores de desempenho para mensurar os objetivos estratégicos onde foram expostas as ações e iniciativas com intuito de operacionalizar a estratégia e corroborar com a gestão da RCC na operacionalização da Gestão Estratégica.

Palavras-Chaves: Periódicos científicos. Balanced scorecard. Avaliação de desempenho.

\begin{abstract}
This study aims to propose the transformation of the strategic action of the Journal of Contemporary Accounting-RCC into operational objectives, based on the approach of the Balanced Scorecard - BSC. This is a case study of a descriptive nature, for data collection were used secondary sources available in the journal study. To build the theoretical framework, we performed a literature search in international journals available on the website of Capes. From this study it was possible to identify the main criteria used for evaluation of these publications. The results pointed to the usefulness of the proposal it has identified 13 goals divided into three perspectives (society, Internal Processes, Learning and Growth). The construction of the panel provided the strategic generation of performance indicators to measure the strategic objectives which were set out the actions and initiatives with the aim to operationalize the strategy and corroborate with the management of RCC in the operationalization of Strategic Management.
\end{abstract}

Keywords: Scientific journals. Balanced scorecard. Performance evaluation.

\section{Introdução}

Para Santos (2007, p. 129), “a palavra periódico é originária do Latim "periatus", que significa espaço de tempo". A publicação expressa o conhecimento científico produzido pela sociedade em determinada época. Segundo Bohn (2003, p. 1), "[o]s periódicos científicos são canais importantes de comunicação, pois registram, divulgam e avaliam o conhecimento de determinada área do saber". Para Arellano (2005), a produção científica possibilita a difusão do conhecimento por meio de livros, revistas e artigos e tem papel destacado no processo de transferência e compartilhamento da informação técnico-científica e construção de conhecimento. Um periódico científico é uma publicação que expressa a ciência produzida pela sociedade em determinada época (SANTOS, 2007).

O presente estudo é direcionado a um periódico científico da área de Contabilidade, a Revista Contemporânea de Contabilidade (RCC), que está em uma fase de aperfeiçoamento de sua gestão. $O$ critério de seleção foi a classificação 
desse periódico no Extrato B3, o que configura a necessidade de um instrumento que auxilie a melhoria de sua classificação e que, ao mesmo tempo, contemple a especificidade e a cultura da RCC. O conselho editorial da revista estudada almeja para 2015 que a revista seja reconhecida nacional e internacionalmente pela sociedade e órgãos reguladores como veículo disseminador de conhecimentos contábeis. Porém os gestores se deparam com o problema de avaliar e operacionalizar essa ação estratégica. Diante desse contexto emerge a seguinte pergunta de pesquisa: Como operacionalizar a ação estratégica para reconhecimento científico da Revista Contemporânea de Contabilidade?

Para responder a essa pergunta de pesquisa, o objetivo geral do presente trabalho é propor a transformação da ação estratégica da revista em objetivos operacionais. Os objetivos específicos que contribuem para o alcance desse objetivo geral incluem: (i) elaborar o mapa estratégico; (ii) estabelecer indicadores de desempenho para acompanhar a implementação das estratégias apresentadas no mapa estratégico; e, (iii) propor ações para consecução dos objetivos estratégicos de curto prazo.

Para a operacionalização dos objetivos estratégicos, nesta pesquisa sugerese a aplicação do Balance Scorecard como instrumento de intervenção. Para Kaplan e Norton (1997), o Balanced Scorecard é uma ferramenta que auxilia as organizações a traduzir a estratégia em objetivos operacionais. Isso permite a construção de um modelo para viabilizar novas estratégias para a evolução da revista RCC.

A relevância deste trabalho pode ser argumentada em termos das contribuições teóricas e práticas que ela pretende oferecer. Com relação à proposta teórico-metodológica, o objetivo é oferecer conhecimento quanto à construção do instrumento de intervenção utilizada para avaliar e operacionalizar a estratégia da revista estudada. Adicionalmente, a proposta se mostra relevante diante da escassez de publicações a respeito de uma metodologia que auxilie os gestores de periódicos científicos na operacionalização de seus objetivos estratégicos. Essa escassez foi percebida na pesquisa bibliográfica realizada em periódicos científicos internacionais disponibilizados no site da Capes e evidenciada no Quadro 1.

Com relação à proposta prática, o artigo propõe a aplicação do Balance Scorecard, um processo estruturado, que irá auxiliar o gestor da RCC, oferecendo-lhe subsídios necessários para auxiliar a gestão no alcance de seus objetivos estratégicos.

Além desta seção de caráter introdutório, o artigo contempla: (i) o referencial teórico; (ii) a metodologia da pesquisa; (iii) a discussão dos dados e resultados da pesquisa; (iv) as considerações finais; e, por fim, (v) as referências utilizadas. 


\section{Revisão Teórica}

A revisão do arcabouço teórico utilizado para a elaboração deste trabalho é dividida em duas etapas. A primeira demonstra o resultado da pesquisa bibliográfica realizada no contexto internacional em relação às ações estratégicas e ferramentas de avaliação sugeridas às revistas científicas, com o intuito de corroborar com seu aperfeiçoamento. Na segunda parte, apresenta o conceito de ações estratégicas e a ferramenta utilizada para operacionalizá-la.

\subsection{Periódico Científico Conforme Manifestado em Artigos do Contexto Inter- nacional}

Com o objetivo de investigar o "estado da arte" em relação às revistas científicas, suas ações e ferramentas estratégicas, realizou-se uma pesquisa das publicações sobre o tema (ver seção 3.2 - Procedimento para a elaboração da pesquisa bibliográfica) resultando em um portfólio bibliográfico utilizado na sustentação teórica da pesquisa. Justifica-se a inclusão do Quadro 1 na seção de revisão teórica pelo fato de apresentar os artigos que compõem o arcabouço teórico que evidencia a necessidade da utilização de instrumentos que auxiliem os gestores a gerenciar as estratégias e ações propostas pelos autores pesquisados. As colunas do Quadro 1 -'Síntese' e 'Ações estratégicas/ ferramentas utilizadas' - mostram a lacuna entre as ações propostas e as ferramentas apresentadas para operacionalização das estratégias dos periódicos científicos, no contexto internacional.

Quadro 1 - Revisão Teórica: Avaliação do periódico científico

\begin{tabular}{|l|l|l|}
\hline Autor/Ano & Síntese do artigo & Ações estratégicas/ Ferramentas \\
\hline & & \\
\hline $\begin{array}{l}\text { Krzizanowski, } \\
\text { Rosaly Favero e } \\
\text { Ferreira, Maria } \\
\text { Cecilia (2001) }\end{array}$ & $\begin{array}{l}\text { O artigo apresenta uma me- } \\
\text { todologia para a avaliação de } \\
\text { aspectos formais e de conteúdos } \\
\text { das publicações periódicas cien- } \\
\text { tificas brasileiras. }\end{array}$ & $\begin{array}{l}\text { Trata- se de uma metodologia que se baseia } \\
\text { em procedimentos pré-estabelecidos, dentre } \\
\text { os quais se destacam: Normatização, duração, } \\
\text { periodicidade, indexação de títulos em base } \\
\text { de dados internacionais, difusão, coleções } \\
\text { em base de dados, colaboração de autores, } \\
\text { distribuição do conteúdo e desempenho geral } \\
\text { da revista. }\end{array}$ \\
\hline $\begin{array}{l}\text { Lee, K.-P.,M. M. } \\
\text { Schotland, et AL. } \\
\text { (2002) }\end{array}$ & $\begin{array}{l}\text { O artigo trata das possibilidades } \\
\text { de profissionais da área médica } \\
\text { selecionarem os periódicos para } \\
\text { leitura, por meio de métodos e } \\
\text { habilidades específicas. }\end{array}$ & $\begin{array}{l}\text { Neste estudo observou-se a recomendação de } \\
\text { avaliação do Fator de Impacto, circulação e } \\
\text { taxas de indexação. }\end{array}$ \\
\hline
\end{tabular}




\begin{tabular}{|c|c|c|}
\hline $\begin{array}{l}\text { Ferreira M.C.G., } \\
\text { Krzizanowski R. } \\
\text { F. }(2003)\end{array}$ & $\begin{array}{l}\text { Trata-se de uma revisão de } \\
\text { literatura sobre a avaliação } \\
\text { de periódico evidenciando a } \\
\text { metodologia utilizada para a } \\
\text { avaliação (critérios). Enfatiza } \\
\text { a necessidade de se cuidar dos } \\
\text { aspectos de conteúdo (mérito) } \\
\text { dos periódicos e da forma de } \\
\text { apresentação. }\end{array}$ & $\begin{array}{l}\text { Ação Estratégica recomendada é a investi- } \\
\text { gação da qualidade dos periódicos em geral } \\
\text { incluindo a qualidade do corpo editorial. }\end{array}$ \\
\hline $\begin{array}{l}\text { Gualberto Buela- } \\
\text { Casal (2003) }\end{array}$ & $\begin{array}{l}\text { Neste artigo, o autor versa } \\
\text { sobre índices bibliométricos e } \\
\text { sobre o processo de avaliação } \\
\text { por pares. }\end{array}$ & $\begin{array}{l}\text { Sugere-se que o avaliador de artigos e ou } \\
\text { revista cientificas utilize-se de um índice de } \\
\text { fator de impacto e análise para o processo de } \\
\text { avaliação. }\end{array}$ \\
\hline $\begin{array}{l}\text { Gualberto Buela- } \\
\text { Casal (2004) }\end{array}$ & $\begin{array}{l}\text { Neste artigo, o autor versa } \\
\text { sobre índices bibliométricos e } \\
\text { sobre o processo de avaliação } \\
\text { por pares. }\end{array}$ & $\begin{array}{l}\text { Discute sobre o processo de avaliação por pa- } \\
\text { res e a utilização de índices bibliométricos. }\end{array}$ \\
\hline $\begin{array}{l}\text { Ulrich Pöschl } \\
\text { (2004) }\end{array}$ & $\begin{array}{l}\text { Pesquisou-se o processo de } \\
\text { avaliação por pares e sugeriu-se } \\
\text { um processo mais dinâmico e } \\
\text { interativo de avaliação, confor- } \\
\text { me o estudo aplicado na revista } \\
\text { Atmospheric Chemistry and } \\
\text { Physics. }\end{array}$ & $\begin{array}{l}\text { Para o autor o modo mais promissor para } \\
\text { melhorias no processo de avaliação de revistas } \\
\text { envolve algumas etapas dentre elas: a revisão } \\
\text { por pares, discussão pública e implantação de } \\
\text { processos de avaliação interativos. }\end{array}$ \\
\hline $\begin{array}{l}\text { Peng Dong, Marie } \\
\text { Loh and Adrian } \\
\text { Mondry, (2005) }\end{array}$ & $\begin{array}{l}\text { O artigo esclarece sobre a gran- } \\
\text { de quantidade de publicações } \\
\text { existentes no mundo e sobre a } \\
\text { necessidade de selecionar o que } \\
\text { há de melhor, utilizando-se do } \\
\text { Fator de Impacto. }\end{array}$ & $\begin{array}{l}\text { Neste estudo o critério utilizado para avalia- } \\
\text { ção da revista é o fator de impacto. }\end{array}$ \\
\hline $\begin{array}{l}\text { Ee-Peng Lim, Ba- } \\
\text { Quy Vuong, Hady } \\
\text { Wirawan Lauw, } \\
\text { Aixin Sun (2006) }\end{array}$ & $\begin{array}{l}\text { O artigo apresenta resultados } \\
\text { de experimentos realizados } \\
\text { com a Wikipedia e seus contri- } \\
\text { buintes. }\end{array}$ & $\begin{array}{l}\text { Estuda o processo científico (Revisão por } \\
\text { pares) de submissão e incorporação de contri- } \\
\text { buições e o Wikpedia que não possui o rigor } \\
\text { científico. }\end{array}$ \\
\hline $\begin{array}{l}\text { Aleixandre Bena- } \\
\text { vent, R.,J. Gon- } \\
\text { zalez-De-Dios, eta } \\
\text { al. }(2007)\end{array}$ & $\begin{array}{l}\text { O artigo trata da avaliação de } \\
\text { aspectos formais da revista } \\
\text { espanhola de pediatria. }\end{array}$ & $\begin{array}{l}\text { Apresenta ações estratégicas em parâmetros } \\
\text { para a avaliação das revistas em cinco grandes } \\
\text { blocos: a apresentação das revistas, apresenta- } \\
\text { ção dos artigos, comissão editorial e científico, } \\
\text { características do conteúdo e parâmetros de } \\
\text { difusão. }\end{array}$ \\
\hline $\begin{array}{l}\text { Christian Kieling, } \\
\text { Renat a Rocha } \\
\text { Fernandes Gon- } \\
\text { çalves, } 2007\end{array}$ & $\begin{array}{l}\text { Os autores apresentam resul- } \\
\text { tados alcançados pela Revista } \\
\text { Brasileira de Psiquiatria (RBP) } \\
\text { após a indexação desta no ISI. }\end{array}$ & $\begin{array}{l}\text { Recomendam ações para melhorar o FI da } \\
\text { revista: 1. Diminuição do tempo de submis- } \\
\text { são e aprovação. 2. A publicação dos artigos } \\
\text { em versão on line. 3. A disponibilização dos } \\
\text { abstracts no Medline e a disponibilidade dos } \\
\text { conteúdos dos artigos em inglês. }\end{array}$ \\
\hline
\end{tabular}




\begin{tabular}{|c|c|c|}
\hline $\begin{array}{l}\text { Ana Ludmila } \\
\text { Freira Costa e } \\
\text { Oswaldo Hajime } \\
\text { Yanomoto, (2008) }\end{array}$ & $\begin{array}{l}\text { O principal objetivo do artigo } \\
\text { é fazer uma meta-avaliação so- } \\
\text { bre o processo de avaliação das } \\
\text { revistas de psicologia. }\end{array}$ & $\begin{array}{l}\text { Recomenda que os objetivos estratégicos dos } \\
\text { periódicos científicos da psicologia, para a } \\
\text { base de dados Qualis, devem se situar em três } \\
\text { pontos: } 1 \text {. Qualificação dos periódicos. } 2 \text {. Cria- } \\
\text { ção de mecanismos voltados à manutenção dos } \\
\text { periódicos mais bem conceituados. 3. Estabe- } \\
\text { lecimento de parâmetros para a melhoria da } \\
\text { qualidade dos títulos da área. }\end{array}$ \\
\hline $\begin{array}{l}\text { Christian Salas, } \\
2008\end{array}$ & $\begin{array}{l}\text { Analisa-se o processo de publi- } \\
\text { cação das revistas científicas } \\
\text { chilenas, considerando-se o } \\
\text { formato, a consistência e a } \\
\text { forma como estão abordando a } \\
\text { temática proposta. }\end{array}$ & $\begin{array}{l}\text { Apresenta algumas ações estratégicas para } \\
\text { melhorar o desempenho da revista, dentre } \\
\text { os quais: 1. Realizar maiores esforços para } \\
\text { ampliar o formato dos artigos. } 2 \text {. Estabelecer } \\
\text { um sistema de envio. } 3 \text {. Reduzir o número de } \\
\text { categorias relacionadas com o tipo de contri- } \\
\text { buições aceitas pela revista. } 4 \text {. Aprimorar o } \\
\text { sistema de avaliação bem como investir na } \\
\text { equipe de editoração. }\end{array}$ \\
\hline $\begin{array}{l}\text { Mo g h a d d a m, } \\
\text { G.G. e M. Mobal- } \\
\text { leghi. 2008. }\end{array}$ & $\begin{array}{l}\text { O autor analisa quatro princi- } \\
\text { pais metodologias de investiga- } \\
\text { ção utilizadas para a validação } \\
\text { de revistas científicas, incluin- } \\
\text { do questionários e entrevista, } \\
\text { citações, análise e operações } \\
\text { pós-análise. }\end{array}$ & $\begin{array}{l}\text { Observou-se a possibilidade de se usarem } \\
\text { novas tecnologias da informação para a com- } \\
\text { plementação de metodologia de pesquisa, em } \\
\text { especial a transação "log" análise e avaliação } \\
\text { do fator de impacto. }\end{array}$ \\
\hline
\end{tabular}

Fonte: Dados da pesquisa.

O Quadro 1 ilustra a evolução de pesquisas desenvolvidas no período entre 1998 e 2008 referentes às revistas científicas. Na literatura científica pesquisada não há consenso a respeito de quais as ações estratégicas são mais adequadas para buscar o reconhecimento científico, apesar de os estudos objetivarem, invariavelmente, a garantia da qualidade das informações que circulam nos periódicos. Entretanto, para a realização de qualquer julgamento, é necessário definir quais os parâmetros a serem levados em consideração e que tipo de dados serão analisados. Contudo, tais escolhas podem resultar em discordâncias e críticas quanto aos critérios adotados (BUELA-CASAL, 2003).

Apesar dessa falta de consenso, constatam-se alguns pontos em comum nos diversos trabalhos sobre as ações estratégicas que possam melhorar a qualidade de periódicos.

\subsection{Avaliação e Operacionalização da Estratégia}

Após a verificação das ações estratégicas e ferramentas utilizadas pelos autores no contexto internacional, buscou-se, na avaliação de desempenho, uma ferramenta capaz de operacionalizar os objetivos estratégicos que representam o que se pretende alcançar. A estratégia pode ser definida como a arte de aplicar 
os meios disponíveis com vistas à consecução de objetivos específicos, a arte de explorar condições favoráveis com o fim de alcançar objetivos determinados (FERREIRA, 1986). Para Chiavenato e Neto (2003, p. 245), estratégia “é o caminho escolhido para posicionar a organização no seu negócio de forma competitiva e garantir sua perpetuação em longo prazo". Schmidt, Santos e Martins (2006) destacam uma proposta de visão integrada entre a formulação, o desdobramento e a implementação de estratégias, já utilizadas em empresas, a saber: Economic Value Added (EVA), Balanced Scorecard (BSC), Modelo Quantum, Modelo dos Três Níveis do Desempenho, Capital Intelectual, Modelo da Teoria das Restrições (TOC), Modelo de Melhoria da Performance, Gestão da Qualidade Total (Modelo TQM) e Benchmarking.

Dos modelos apresentados, o BSC é o mais utilizado para operacionalizar a estratégia. Segundo Zorzi e Ensslin (2007), o Balanced Scorecard é um sistema de gerenciamento que permite às organizações clarificarem sua visão e estratégia para todos os seus componentes e traduzi-las em planos de ação. O Balanced Scorecard tem como função medir o desempenho empresarial dentro das seguintes perspectivas: financeira, do cliente, dos processos internos da empresa e do aprendizado e crescimento (KAPLAN; NORTON, 1997; MANBRINI; BEUREN; COLAUTO, 2005). Essas perspectivas, no entanto, podem ser moldadas de acordo com as necessidades de cada organização. Segundo Kaplan e Norton (2000, p. 13), "todos os objetivos e indicadores do Balanced Scorecard - financeiros e não financeiros - devem emanar da visão e da estratégia da organização”. Para Kaplan, Norton (1997, p. 30), os objetivos e indicadores de desempenho utilizados na realização de um Balanced Scorecard não se limitam a um conjunto aleatório de medidas de desempenhos financeiros e não financeiros, pois fazem parte de um processo hierárquico norteado pela missão e pela estratégia da unidade de negócio.

\section{Metodologia da Pesquisa}

Esta seção do trabalho aborda: (i) o enquadramento metodológico; (ii) os procedimentos para revisão da literatura; e (iii) o instrumento de intervenção selecionado para auxiliar a gestão da revista a operacionalizar seus objetivos estratégicos.

\subsection{Enquadramento metodológico}


Figura 1 - Enquadramento metodológico da pesquisa

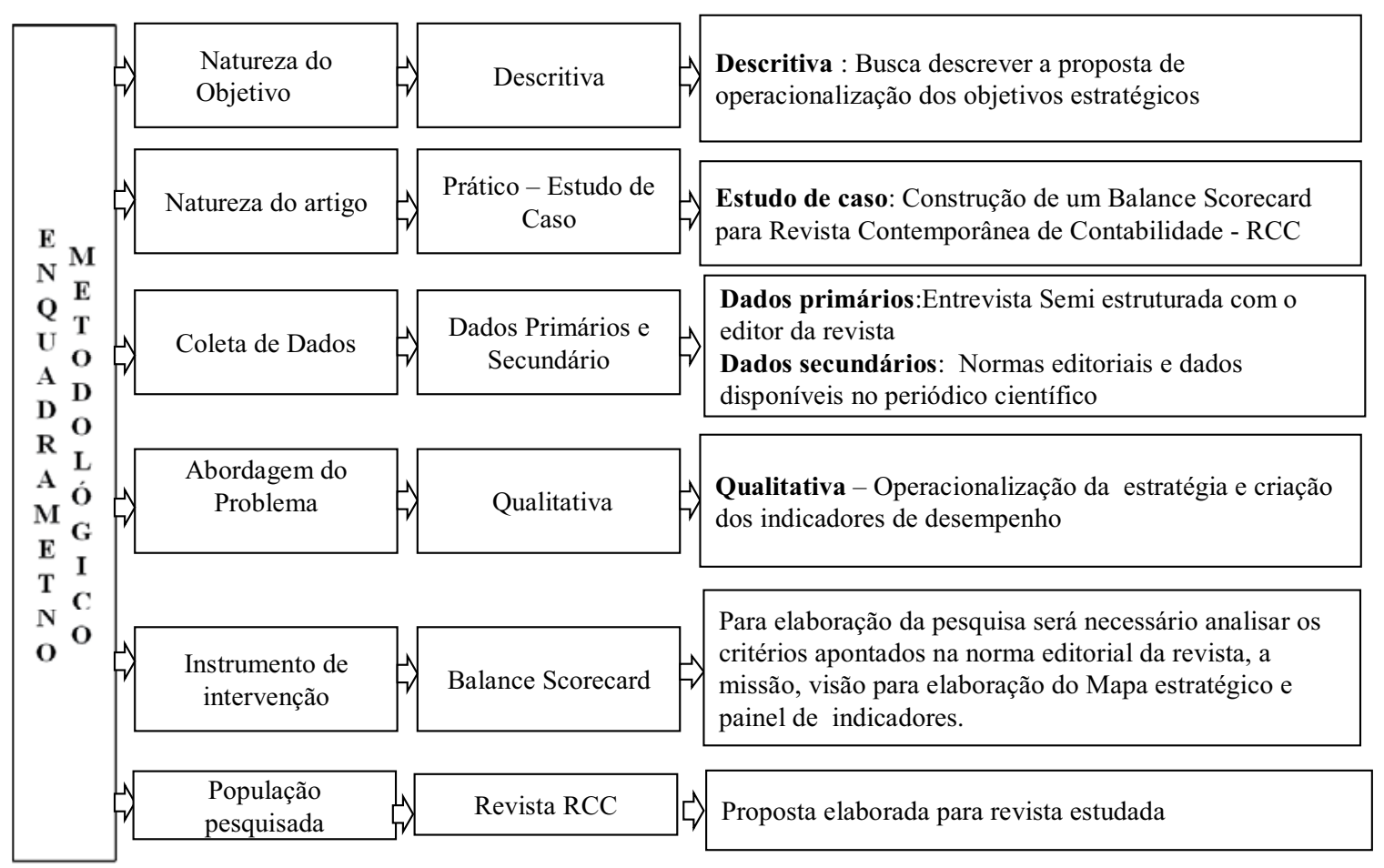

Fonte: Dados da pesquisa.

\subsection{Procedimento para a Elaboração da Pesquisa Bibliográfica}

O procedimento estruturado para seleção do arcabouço teórico desta pesquisa divide-se em duas fases: (i) Seleção das bases de dados; e, (ii) Seleção dos artigos.

\subsubsection{Seleção das Bases de Dados}

A pesquisa bibliográfica foi realizada em periódicos internacionais localizados na coleção de bibliotecas eletrônicas (bases de dados) disponibilizadas no portal Capes, no período de 1998 a 2008. O primeiro passo para a elaboração do processo de seleção do referencial bibliográfico consiste na seleção das áreas/ temas vinculados à pesquisa e avaliação de periódicos: Multidisciplinar, Ciências Exatas e da Terra, Ciências Sociais Aplicadas, Ciências Humanas e Ciências da Saúde. Como o tema de pesquisa abrange diversas áreas de conhecimento, selecionaram-se as bases de dados que, em sua definição, contenham pelo menos uma das áreas de conhecimentos vinculadas ao tema da pesquisa. Para realização deste trabalho, foram escolhidas 23 bases de dados de textos completos e 19 bases de dados de resumos. 
3.2.2 Seleção dos Artigos

Nas bases de dados selecionadas, pesquisaram-se as palavras-chave: Scientific journals, Scientific Periodicals, Scientific magazine. As palavras foram pesquisadas individualmente nos resumos ou (or) títulos ou (or) palavras-chave. A pesquisa resultou em uma amostra de 3.843 artigos que foram importados para um gerenciador bibliográfico. Após a importação, foram excluídos os documentos que não eram de interesse científico e os duplicados.

Essas ações resultaram em uma redução da amostra em 978 artigos, com isso o total do portfólio de artigos pesquisados passou para 2.865 artigos. Logo após iniciou-se a leitura dos títulos e a exclusão dos artigos não alinhados com o tema de pesquisa. Os autores da pesquisa definiram que os títulos alinhados são aqueles que contemplem pelo menos um dos assuntos: avaliação de desempenho, avaliação dos periódicos científicos, qualidade das revistas científicas, qualidade nas publicações, índices bibliométricos e processo editorial. Após essa fase restaram 92 artigos candidatos a compor o portfólio desta pesquisa.

A próxima etapa é analisar a representatividade científica dos artigos selecionados. Para isso, verificou-se o número de citação de cada artigo no site Google Acadêmico. Após a identificação dos artigos mais citados, foram lidos os resumos para compor o portfólio desta pesquisa em termos de alinhamento e/ou de atualidade e/ou de autores. Após a análise, selecionou-se o arcabouço teórico composto por 13 artigos que tratam da avaliação de periódicos científicos. Os artigos selecionados estão dispostos no Quadro 1 (Seção 2.1 Periódico científico conforme manifestado em artigos do contexto internacional).

\subsection{Procedimento para Aplicação do Instrumento de Intervenção}

Este tópico possui o intuito de apresentar o Balance Scorecard, ferramenta utilizada para operacionalizar as estratégias da Revista Contemporânea de Contabilidade. Roberto (2006) descreve que o Balanced Scorecard é apresentado na literatura técnica como instrumento de gestão que possibilita o alinhamento da organização com sua estratégia, viabilizando os processos gerenciais críticos. Para identificar a estratégia da empresa estudada, primeiro gera-se conhecimento sobre ela por meio da contextualização.

Na elaboração da contextualização, utilizaram-se informações encontradas na política editorial, nas pesquisas de acesso, nas informações disponibilizadas na base onde a revista é indexada e nos volumes já publicados desde 2004, bem como os artigos neles disponibilizados e as informações sobre os Curriculum Lattes dos envolvidos no processo editorial, inclusive dos avaliadores ad hoc. Além das informações citadas, foi conferido se a revista atende aos critérios de qualidade 
apontados pela Capes. De posse dessas informações, foram identificados os objetivos estratégicos da revista e organizados nas perspectivas do BSC.

Como o periódico estudado possui como atividade disseminar conhecimento científico de Contabilidade para a sociedade e não objetiva o lucro, o desdobramento da estratégia deu-se em três perspectivas: Sociedade, Processos Internos e Aprendizado e Crescimento. Nas perspectivas selecionadas, desdobraram-se os objetivos estratégicos (ver Quadro 2 - seção 4.1 - Identificação dos objetivos estratégicos) que foram organizados no mapa de relação meios fins. Logo após o desdobramento dos elementos no mapa de relação meios fins, foi definido o painel estratégico (ver Quadro 3 - seção 4.2 - Elaboração do mapa de relações meios fins) com os objetivos alvos, indicadores de desempenhos da situação atual e da situação pretendida e ações de melhorias a curto prazo sugeridas pelos autores desta pesquisa para auxiliar a gestão do periódico estudado.

\section{Operacionalização da Proposta: Discussão dos Dados e Resutlados da Pesquisa no Estudo de Caso}

Nesta seção, apresenta-se a aplicação do instrumento de intervenção que está dividida em três fases de acordo com o proposto nos objetivos específicos sendo elas: (i) identificação dos objetivos estratégicos; (ii) elaboração do mapa de relações meios fins dos objetivos identificados; e, (iii) construção do painel estratégico.

\subsection{Identificação dos Objetivos Estratégicos}

Para a identificação dos objetivos estratégicos é necessário contextualizar o objeto de estudo: Revista Contemporânea de Contabilidade. A instituição estudada é um periódico científico que disponibiliza textos completos na área de Contabilidade com edições semestrais. A política de acesso é livre, indexada no Redalyc e está classificada como periódico B3 Qualis/Capes. O propósito essencial da revista é "interagir com diferentes públicos e instituições no que diz respeito aos conhecimentos contábeis, tanto em nível nacional como internacional, divulgar e fomentar o desenvolvimento de metodologias e procedimentos nas áreas do ensino, da pesquisa e da extensão em atividades contábeis, e contribuir para a formação humana e profissional nos limites das discussões e possibilidades das Ciências Econômicas e Sócio-Aplicadas".

Buscou-se na literatura especializada a identificação das ações que auxiliarão os editores da revista a operacionalizar estratégias de reconhecimento científico. A partir das ações estratégicas pesquisadas no referencial teórico, das informações pesquisadas no processo editorial e do levantamento do referencial 
bibliográfico no contexto internacional, propõem-se objetivos estratégicos. O Quadro 3 apresenta as perspectivas, os objetivos estratégicos e seus significados.

\section{Quadro 3 - Identificação dos objetivos estratégicos}

\begin{tabular}{|c|c|c|c|}
\hline & Área & Objetivo Estratégico & Significados \\
\hline \multirow[b]{3}{*}{$\begin{array}{l}\frac{0}{\pi} \\
\frac{\pi}{0} \\
\frac{0}{0} \\
0 \\
0\end{array}$} & \multirow{3}{*}{ 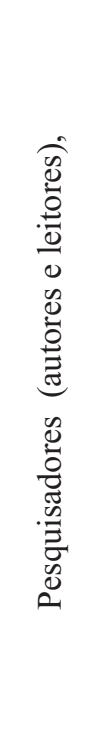 } & $\begin{array}{l}\text { Ser referência entre os pesquisadores, } \\
\text { fazendo com que tenham a RCC como } \\
\text { sua primeira opção para a submissão e } \\
\text { pesquisa de artigos }\end{array}$ & $\begin{array}{l}\text { Estar entre os melhores revista } \\
\text { Possuir elevado numero de citações } \\
\text { Possuir ampla cobertura de abrangência } \\
\text { aperfeiçoar instrumentos tecnológicos que facilite a } \\
\text { pesquisa na revista } \\
\text { Disseminar o conhecimento contábil nacional e } \\
\text { internacionalmente } \\
\text { Pos }\end{array}$ \\
\hline & & $\begin{array}{l}\text { Ser classificada pelos órgãos reguladores } \\
\text { como revistas (A) nacional e internacional }\end{array}$ & $\begin{array}{l}\text { Atender os critérios de qualidade apontados pelos } \\
\text { órgãos reguladores em relação: } \\
\text { Periódicos } \\
\text { Artigos } \\
\text { Colaboradores }\end{array}$ \\
\hline & & Ampliar Rede de Relacionamento & $\begin{array}{l}\text { Universidades Nacionais e internacionais } \\
\text { Bases de dados Nacional e internacional } \\
\text { Órgãos reguladores } \\
\text { Associações e entidades }\end{array}$ \\
\hline \multirow{6}{*}{$\begin{array}{l}n \\
0 \\
\Xi \\
0 \\
\Xi \\
\Xi \\
0 \\
0 \\
0 \\
0 \\
0 \\
0 \\
0 \\
0\end{array}$} & \multirow{2}{*}{ 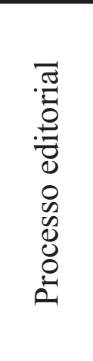 } & $\begin{array}{l}\text { ter processo para garantir os recursos } \\
\text { necessários para funcionamento da revista }\end{array}$ & $\begin{array}{l}\text { Viabilizar os recursos necessários para funcionamento } \\
\text { da revista - Governo } \\
\text { Orgãos de Formento } \\
\text { Doações }\end{array}$ \\
\hline & & $\begin{array}{l}\text { Aumentar a eficiência do processo } \\
\text { editorial }\end{array}$ & $\begin{array}{l}\text { Captar artigos de interesse da área } \\
\text { Possuir processo editorial consistente e transparente } \\
\text { para seleção dos artigos } \\
\text { Diminuir o tempo de publicação da revista }\end{array}$ \\
\hline & 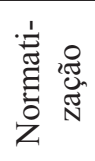 & $\begin{array}{l}\text { Ter processo para atender a normatização } \\
\text { imposta pelo os orgãos reguladores }\end{array}$ & Atender os requisitos de qualidade necessários \\
\hline & \multirow{3}{*}{ 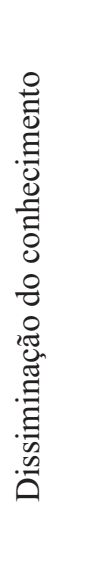 } & $\begin{array}{l}\text { Ter processo que objetiva aumentar o } \\
\text { numero de citação da revista }\end{array}$ & $\begin{array}{l}\text { Incluir a revista no maior número possível de bases de } \\
\text { dados. } \\
\text { Publicado artigos em Inglês. } \\
\text { Publicar artigos sobre temas da atualidade. } \\
\text { Publicar artigos amplamente citados pelos autores. } \\
\text { Fazer promoções com os meios de comunicação. } \\
\text { Recomendar cit }\end{array}$ \\
\hline & & $\begin{array}{l}\text { Ter processo que objetiva aumentar a área } \\
\text { de abrangência da pesquisa }\end{array}$ & Aumentar a participação em bases de dados \\
\hline & & $\begin{array}{l}\text { Ter um processo para conquistar novas } \\
\text { parcerias }\end{array}$ & $\begin{array}{l}\text { fazer convênios com Universidades brasileiras e no } \\
\text { exterior } \\
\text { Cursos de Pós graduação (Nacionais e internacioanis) } \\
\text { Associações e Entidades de Classe }\end{array}$ \\
\hline
\end{tabular}




\begin{tabular}{|c|c|c|c|}
\hline & Área & Objetivo Estratégico & Significados \\
\hline \multirow{6}{*}{ 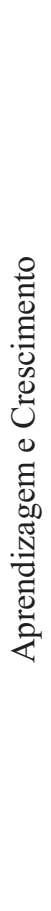 } & \multirow{2}{*}{ 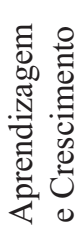 } & Manter atualizada a infra-estrutura & $\begin{array}{l}\text { Manter o Sistema de Gerenciamentos (SER) } \\
\text { Site atualizados }\end{array}$ \\
\hline & & Captar talentos humanos & $\begin{array}{l}\text { Conquistar novos colaboradores para participar do } \\
\text { processo captação, avaliação e }\end{array}$ \\
\hline & 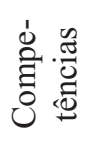 & Desenvolver pessoas & $\begin{array}{l}\text { Treinar os participantes do processo editorial em rela- } \\
\text { ção a captação, avaliação e seleção dos artigos }\end{array}$ \\
\hline & \multirow{2}{*}{ 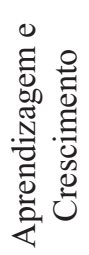 } & Manter atualizada a infra-estrutura & $\begin{array}{l}\text { Manter o Sistema de Gerenciamentos (SER) } \\
\text { Site atualizados }\end{array}$ \\
\hline & & Captar talentos humanos & $\begin{array}{l}\text { Conquistar novos colaboradores para participar do } \\
\text { processo captação, avaliação e }\end{array}$ \\
\hline & 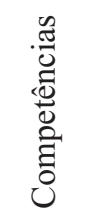 & Desenvolver pessoas & $\begin{array}{l}\text { Treinar os participantes do processo editorial em rela- } \\
\text { ção a captação, avaliação e seleção dos artigos }\end{array}$ \\
\hline
\end{tabular}

Fonte: Dados da pesquisa.

A partir da explicitação dos objetivos estratégicos, as relações de causa e efeito entre os objetivos foram definidas e representadas no mapa estratégico.

\subsection{Elaboração do Mapa de Relações Meios Fins}

Para Ensslin, Souza, Dias (2008), Serra et al. (2006), no mapa estratégico, as perspectivas são colocadas em foco, e as relações de causa e efeito são demonstradas. A Figura 2 apresenta o mapa estratégico e suas relações de causa e efeito. 


\section{Figura 2 - Mapa estratégico}

RCC 2015

Ser reconhecida Nacional e Internacionalmente pela sociedade científica e órgãos reguladores como veículo disseminador de conhecimentos Contábeis.

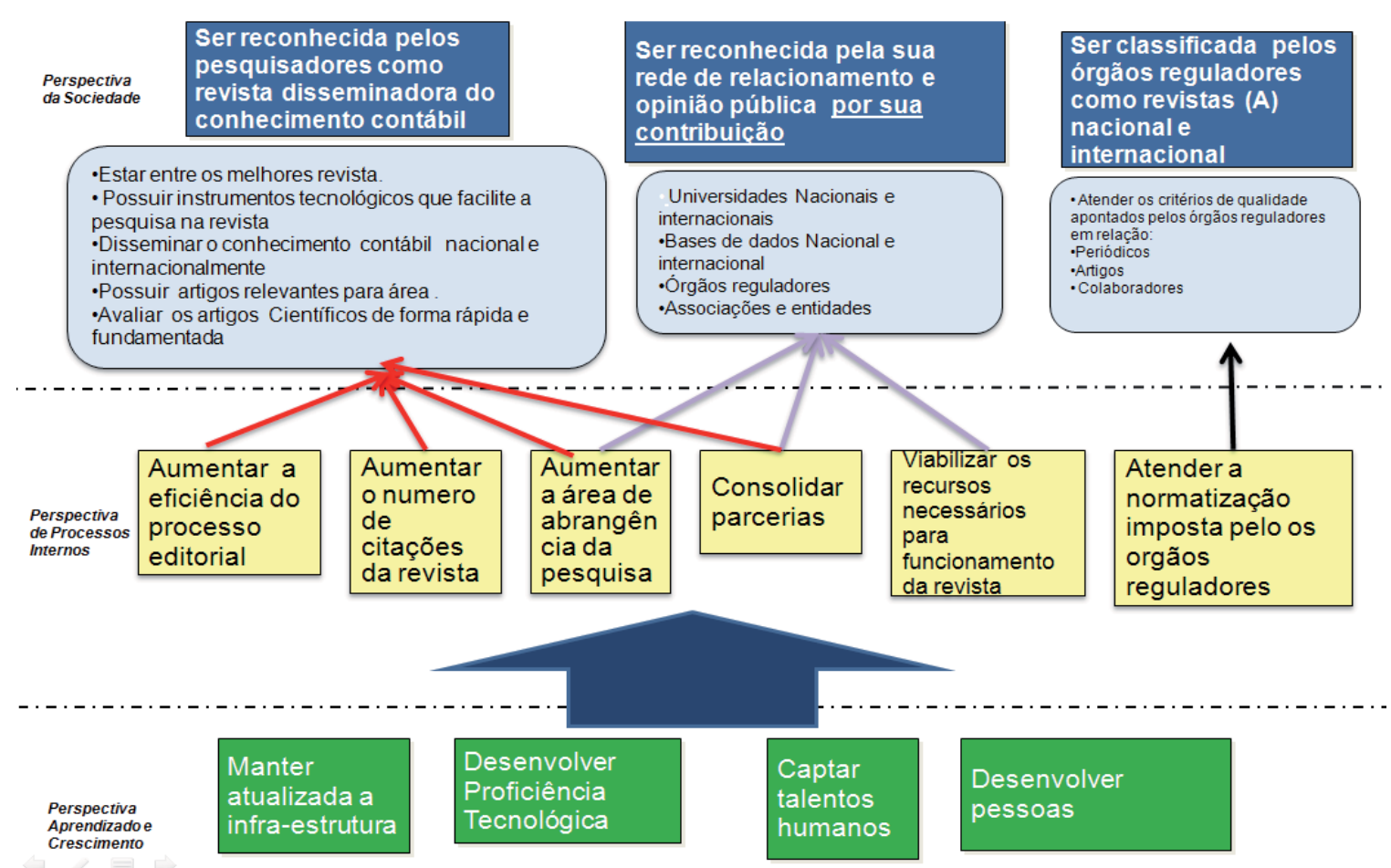

Fonte: Dados da pesquisa..

Os dados da Figura 2 revelam que, na Perspectiva da Sociedade, as relações se concentram em ser reconhecidas pelos pesquisadores como revista disseminadora de conhecimento contábil. Quanto ao processo interno, os objetivos visam aumentar a eficiência do processo editorial e consolidar parcerias. Por sua vez, na Perspectiva Aprendizado e Crescimento, as relações de causa e efeito concentramse em captar talentos humanos e desenvolver pessoas. Essas ações visam aumentar a eficiência do processo editorial, aumentar o número de citações da revista, consolidar parcerias, viabilizar os recursos necessários para o funcionamento da revista e atender à normalização imposta pelos órgãos reguladores.

Quanto à hierarquização das perspectivas, no mapa estratégico, utilizaramse os fundamentos propostos por Kaplan e Norton (ver Seção 3.3 - Procedimentos para aplicação do instrumento de intervenção), porém optou-se em propor um diagrama de causa e efeito, de acordo com os objetivos estratégicos do periódico estudado.

Após a construção do Mapa de Relação Meios Fins, passou-se para fase de construção do painel estratégico.

\subsection{Construção do Painel Estratégico}


O Painel da RCC foi construído para representar as três perspectivas estratégicas (Sociedade, Processos Internos e Aprendizagem e Crescimento) e seus objetivos estratégicos que serão avaliados pelo conjunto de indicadores de desempenho com intuito de acompanhar as metas propostas.

Quadro 3 - Painel Estratégico

\begin{tabular}{|c|c|c|c|c|c|}
\hline & Objetivos & Indicadores & $\begin{array}{l}\text { situação } \\
\text { atual }\end{array}$ & Meta 2014 & $\begin{array}{c}\text { Iniciativas de curto } \\
\text { prazo }\end{array}$ \\
\hline \multirow{3}{*}{$\begin{array}{l}\frac{\pi}{0} \\
\frac{\pi}{0} \\
\frac{0}{0} \\
0 \\
0\end{array}$} & $\begin{array}{l}\text { Ser referência entre os } \\
\text { pesquisadores, fazendo } \\
\text { com que tenham a RCC } \\
\text { como sua primeira } \\
\text { opção para a submissão } \\
\text { e pesquisa de artigos }\end{array}$ & N. de acesso a revista & $\begin{array}{l}\text { estima-se } \\
19.290 \text { no } \\
\text { ano/2009 }\end{array}$ & $\begin{array}{l}\text { aumentar } \\
\text { em } 400 \%\end{array}$ & $\begin{array}{l}\text { Disponibilizar artigos, } \\
\text { entrevistas e resenhas: De } \\
\text { autores renomanos, temas } \\
\text { controversos, temas atuais } \\
\text { e emergentes da area } \\
\text { contábil }\end{array}$ \\
\hline & $\begin{array}{l}\text { Ser classificada pelos } \\
\text { órgãos reguladores } \\
\text { como revistas (A) nacio- } \\
\text { nal e internacional }\end{array}$ & $\mathrm{N}^{\mathrm{o}}$ de classificação & B4 & A & $\begin{array}{l}\text { Atender os quesitos suge- } \\
\text { ridos pela área }\end{array}$ \\
\hline & $\begin{array}{l}\text { Ampliar Rede de Rela- } \\
\text { cionamento }\end{array}$ & $\begin{array}{l}\% \text { de cresciemento de } \\
\text { usuários da rede dos } \\
\text { usuários nacionais / \% de } \\
\text { cresciemento de usuários } \\
\text { da rede dos usuários } \\
\text { internacionais }\end{array}$ & 26 & $\begin{array}{c}\text { aumentar } \\
160 \%\end{array}$ & $\begin{array}{l}\text { Fazer ações pormocionais } \\
\text { para divulgar a revista }\end{array}$ \\
\hline \multirow{6}{*}{$\begin{array}{l}0 \\
0 \\
0 \\
0 \\
\Xi \\
0 \\
0 \\
0 \\
0 \\
0 \\
0 \\
0 \\
0 \\
0\end{array}$} & $\begin{array}{l}\text { ter processo para garan- } \\
\text { tir os recursos necessá- } \\
\text { rios para funcionamento } \\
\text { da revista }\end{array}$ & $\begin{array}{l}\mathrm{N}^{\mathrm{o}} \text { de patrocinadores } \\
\text { externo }\end{array}$ & 2 & $\begin{array}{l}\text { aumentar } \\
200 \%\end{array}$ & $\begin{array}{l}\text { Indentificar os possiveis } \\
\text { patrocinadores dispostos a } \\
\text { investir na revista }\end{array}$ \\
\hline & $\begin{array}{l}\text { Aumentar a eficiência } \\
\text { do processo editorial }\end{array}$ & $\begin{array}{l}\text { Tempo entre a publicação } \\
\text { da edição do preriódico }\end{array}$ & 2 anos & 6 meses & $\begin{array}{l}\text { Premiar avaliadores ad hoc } \\
\text { em destaque / Divulgar a } \\
\text { revista em eventos/asso- } \\
\text { ciações de classe incenti- } \\
\text { vando o envio de artigos }\end{array}$ \\
\hline & $\begin{array}{l}\text { Ter processo para } \\
\text { atender a normatização } \\
\text { imposta pelo os orgãos } \\
\text { reguladores }\end{array}$ & $\begin{array}{l}\text { Percentual de atendimen- } \\
\text { to das normas }\end{array}$ & $95 \%$ & $100 \%$ & $\begin{array}{l}\text { Conferir periódicamente } \\
\text { se todos os quesitos estão } \\
\text { sendo atendidos }\end{array}$ \\
\hline & $\begin{array}{l}\text { Ter processo que obje- } \\
\text { tiva aumentar o numero } \\
\text { de citação da revista }\end{array}$ & $\begin{array}{l}\text { Quatidade de artigos em } \\
\text { ingles }\end{array}$ & 1 & 3 & $\begin{array}{l}\text { Promover ações de incen- } \\
\text { tivo para captar artigos } \\
\text { em ingles }\end{array}$ \\
\hline & $\begin{array}{l}\text { Ter processo que obje- } \\
\text { tiva aumentar a área de } \\
\text { abrangência da pesquisa }\end{array}$ & $\mathrm{N}^{\mathrm{o}}$ de bases indexadas & 1 & 4 & $\begin{array}{l}\text { Adequar a revista as exi- } \\
\text { gências das bases de dados } \\
\text { almejada }\end{array}$ \\
\hline & $\begin{array}{l}\text { Ter um processo para } \\
\text { conquistar novas par- } \\
\text { cerias }\end{array}$ & $\begin{array}{l}\text { (Parcerias Fimadas/ par- } \\
\text { cerias Planejadas )*100 }\end{array}$ & 6 & $\begin{array}{l}\text { aumentar } \\
\text { em } 160 \%\end{array}$ & $\begin{array}{l}\text { Firmar parecerias entre a } \\
\text { revista e universidades, } \\
\text { associações (nacionais e } \\
\text { internacioais) }\end{array}$ \\
\hline
\end{tabular}




\begin{tabular}{|c|c|c|c|c|c|}
\hline & Objetivos & Indicadores & $\begin{array}{l}\text { situação } \\
\text { atual }\end{array}$ & Meta 2014 & $\begin{array}{c}\text { Iniciativas de curto } \\
\text { prazo }\end{array}$ \\
\hline \multirow{4}{*}{ 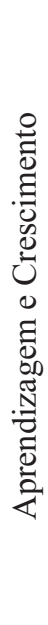 } & $\begin{array}{l}\text { Manter atualizada a } \\
\text { infra-estrutura }\end{array}$ & $\begin{array}{l}\text { \% de atualização do } \\
\text { sistema }\end{array}$ & NT & NT & $\begin{array}{l}\text { atualizar o sistema de edi- } \\
\text { toração continuamente }\end{array}$ \\
\hline & $\begin{array}{l}\text { Desenvolver Proficiên- } \\
\text { cia Tecnológica }\end{array}$ & $\begin{array}{l}\text { (Orçamento de inf. } \\
\text { Tecnológica ( executa- } \\
\text { do)/ orç. De infra tec. } \\
(\text { planejado) }) * 100\end{array}$ & & & $\begin{array}{l}\text { Investir em estrutura } \\
\text { tecnólogica }\end{array}$ \\
\hline & Captar talentos humanos & $\begin{array}{l}\text { (Novos colaboradore } \\
\text { (acum.) /necessidade de } \\
\text { novos colaboradores)* } \\
100\end{array}$ & 34 & $\begin{array}{l}\text { aumentar } \\
\text { em } 30 \%\end{array}$ & $\begin{array}{l}\text { Conquistar novos colabo- } \\
\text { radores. }\end{array}$ \\
\hline & Desenvolver pessoas & $\begin{array}{l}\text { \% de avaliadores que nos } \\
\text { ultimos } 2 \text { anos realizaram } \\
\text { autalizações em relação } \\
\text { ao processo editorial }\end{array}$ & $50 \%$ & $80 \%$ & $\begin{array}{l}\text { Promover ações de } \\
\text { incentivo a atualização dos } \\
\text { avaliadores Ad Hoc }\end{array}$ \\
\hline
\end{tabular}

Fonte: Dados da pesquisa..

Os indicadores do Painel Estratégico (Quadro 3) foram construídos com base nas relações de causa e efeito, sendo assim o indicador avalia individualmente o alcance das metas, dos objetivos estratégico, dos resultados encontrados e impactam diretamente nos resultados da perspectiva adjacente. Para exemplificar, essa relação destaca o indicador (Novos colaboradores (acum.)/necessidade de novos colaboradores)* 100 , que mensura o objetivo captar novos colaboradores da Perspectiva Aprendizagem e Crescimento. Aumentando o número de colaboradores é possível segregar tarefas e melhorar o tempo entre a publicação da edição do periódico. O tempo de publicação é o indicador de desempenho de curto prazo que mensura a eficiência do processo editorial das Perspectiva Processos Internos. Por sua vez, melhorando a eficiência do processo editorial, acredita-se que melhorará a credibilidade da revista com os autores e pesquisadores da Perspectiva adjacente Sociedade.

Além dos indicadores e metas dispostas no Painel Estratégico (Quadro 3 ), os autores apontam algumas ações de curto prazo com objetivo de auxiliar a gestão da revista no atendimento das metas propostas. Para ilustrar a aplicação das ações em relação às metas, seleciona-se o objetivo: Aumentar o número de citação da revista, que na perspectiva processos internos significa: Ter processos que objetivem aumentar o número de citação da revista. Esse objetivo é mensurado pela quantidade de artigos disponibilizados pela revista em inglês. Sendo assim, a sugestão imediata seria promover ações de incentivo à captação de artigos escritos em inglês. Essa ação poderá viabilizar pesquisas e o acesso de pesquisadores de outros países aos artigos publicados. 


\section{Considerações Finais}

No contexto da gestão de periódicos científicos o presente trabalho teve por objetivo propor a operacionalização das estratégias da revista em objetivos operacionais. A partir do objetivo principal, foram formulados três objetivos específicos: (i) elaborar o mapa estratégico; (ii) estabelecer indicadores de desempenho para acompanhar a implementação das ideias apresentadas no mapa estratégico; (iii) propor ações para consecução dos objetivos estratégicos de curto prazo. $\mathrm{Na}$ elaboração do mapa estratégico (objetivo i) foram identificados 13 objetivos distribuídos em três perspectivas: Sociedade, Processos Internos e Aprendizagem e Crescimento. A construção do painel estratégico proporcionou a geração dos indicadores de desempenho (objetivo ii) para mensurar os objetivos estratégicos onde foram expostas as ações e iniciativas com intuito de corroborar com a gestão da RCC na operacionalização da Gestão Estratégica

Nesse sentido, os autores acreditam que a pesquisa aqui relatada e o processo dela resultante possam oferecer uma contribuição efetiva para operacionalizar as ações estratégicas e auxiliar o processo de gestão da revista estudada.

Como limitações da pesquisa, apontam-se os seguintes aspectos: (i) o não acesso aos resultados financeiros da revista; (ii) a operacionalização da proposta teórico-metodológica; (iii) a operacionalização da proposta em apenas um periódico científico. A partir das limitações apontadas, sugerem-se os seguintes tópicos para futuras pesquisas: (i) análise da situação financeira da revista, com o objetivo de verificar a necessidade de implementação da perspectiva financeira ou a inserção desse objetivo estratégico em processos internos que atendam à necessidade da gestão organizacional; (ii) acompanhamento da implementação da proposta teórico-metodológica na RCC; (iii) replicação da proposta teóricometodológica em outro periódico científico, a fim de verificar a similaridade, ou não, de preocupações entre gestores da mesma área de conhecimento.

\section{Referências}

ALEIXANDRE- BENAVENT, R., J. GONZALES-De-Dios, et al. Evaluacion de los aspectos formales de las revistas pediatricas espanolas. Anales de pediatria Barcelona, Spain 2003, v. 66, n. 3, p. 272-81. 2007.

ARELLANO, Miguel Angel Mardero; MORENO, Fernanda Passini. PUBLICAÇÃO CIENTÍFICA EM ARQUIVOS DE. Arquivística Net, Rio de Janeiro,, v. 1, n. 1, p. 76-86, ? jan. 2005. jan./.jun. 2005. Disponível em: <www.arquivistica. net>. Acesso em: 4 abr. 2008. 
Buela-Casal, G. Evaluacion de la calidad de los articulos y de las revistas cientificas: Propuesta del factor de impacto ponderado y de un indice de calidad / Evaluating quality of articles and scientific journals. Proposal of weighted impact factor and a quality index? Psicothema, v. 15, n. 1, p. 23-35. 2003.

BOHN, Maria Del Carmen Rivera. Autores E Autoria Em Periódicos Brasileiros De Ciência Da Informação. R. Eletr. Bibliotecon. Ci. Inf, Florianópolis,, n. 16, p. 1-19, 2003. Semestral. Disponível em: <http://www.periodicos.ufsc.br/index. php/eb>. Acesso em: 2 maio 2008.

COSTA, Ana Ludmila Freire; YAMAMOTO, Oswaldo Hajime. PUBLISHING AND EVALUATING SCIENTIFIC JOURNALS: QUALIS ASSESSMENT IN PSYCHOLOGY. Psicologia em Estudo, Maringá, v. 13, n. 1, p. 13-24, 2008.

DONG, P., M. Loh, et al. The "impact factor" revisited. Biomedical digital libraries, p. 7. 2005.

FERREIRA, M. C. e R. F. Krzyzanowski. Avaliação dos periódicos científicos técnicos Brasileiros, Ci. Inf., Brasília, v. 27, n. 2, p. 165-175, maio/ago. 1998.

FERREIRA, M. C. e R. F. Krzyzanowski. Scientific periodicals: quality criteria. Periodicos cientificos: criterios de qualidade., v.17 Suppl 1, p. 43-48. 2003.

KAPLAN, R. S.; NORTON, D. P. A estratégia em ação: Balanced Scorecard. Tradução Luiz Euclydes Trindade Frazão Filho. Rio de Janeiro: Elsevier, 1997.

KAPLAN, Robert S., NORTON, David P. Organização orientada para a estratégia: como as empresas que adotam o balanced scorecard prosperam no novo ambiente de negócios. Rio de Janeiro: Campus, 2000.

KIELING, Christian; GONÇALVES, Renata Rocha Fernandes. Assessing the quality of a scientific journal: the case of Revista Brasileira de Psiquiatria. Rev Bras Psiquiatr., São Paulo, v. 2, n. 29, p. 177-181, 2007.

LEE, K.-P., M. SCHOTLAND et al. Association of journal quality indicators with methodological quality of clinical research articles. JAMA (Journal of the American Medical Association), v. 287, n. 21, p. 2805-2808. 2002.

MAMBRINO, A., BEUREN, I. M., COLAUTO, R. D., Proposta de Integração dos Planejamentos Estratégico e Operacional ao Balanced Scorecard: O caso de uma rede de empresas. Revista Contemporânea de Contabilidade, v. 1, n. 4, p. 73-97, jul./dez., 2005. 
MOGHADDAM, G.-G. e M. MOBALLEGHI. How do we measure the use of scientific journals? A note on research methodologies. Scientometrics, v. 76, n. 1, p. 125-133. 2008.

PÖSCHL, Ulrich. Journal concept for improved scientific publishing and quality assurance. Learned Publishing, Munich, Germany, v. 17, n. 2, p. 105-113, 2004.

SALAS, Christian. Sugerencias para mejorar la calidad de las revistas científicas chilenas:una aplicación en las ciencias forestales con Bosque. Bosque, Chile, n. , p. 2-10, 2008.

SANTOS, Carmelita do Espirito. REQUISITOS BÁSICOS PARAAVALIAÇÃO DE PERIÓDICOS. Revista Digital de Biblioteconomia e Ciência da Informação, Campinas, v. 5, n. 1, p.129-144, ? jan. 2007. Semestral. Relato. Disponível em: $<$ http://server01.bc.unicamp.br/seer/ojs/>. Acesso em: 29 abr. 2008.

SOUZA, J. V.; DIAS, J. S. ENSSLIN, L. Balanced Scorecard: uma análise estatística das relações de causa e efeito. In: Congresso Brasileiro de Custos, 2008, Curitiba. XV Congresso Brasileiro de Custos, 2008.

ROBERTO, F. A utilização do Balanced Scorecard como instrumento de apoio à gestão estratégica do valor do ativo em clientes. In: CONGRESSO BRASILEIRO DE CUSTOS, 13., 2006. Belo Horizonte, Minas Gerais, 2006.

ZORZI, A.; ENSSLIN, L. Gestão do setor de Contabilidade de uma entidade fechada de previdência complementar com base nas ferramentas BSC MCDA-C. Revista Contemporânea de Contabilidade, v. 4, n. 7, p. 101-124, jan./jun., 2007. 